\title{
Infecção experimental por Salmonella enterica subespécie enterica sorotipo Panama e tentativa de transmissão nasonasal em leitões desmamados
}

\author{
[Experimental infection by Salmonella enterica ssp. enterica serovar Panama and \\ tentative of nose-to-nose transmission in weaned pigs] \\ L.G. Oliveira ${ }^{1}$, L.F.O.S. Carvalho ${ }^{2}$, G.C.I.H. Masson ${ }^{1}$, M.A.R. Feliciano ${ }^{1}$ \\ ${ }^{1}$ Aluno de pós-graduação - FCAV-UNESP - Jaboticabal, SP \\ ${ }^{2}$ Faculdade de Ciências Agrárias e Veterinárias - UNESP \\ Via de Acesso Prof. Paulo Donato Castellane, s/n \\ 14884-900 - Jaboticabal, SP
}

\begin{abstract}
RESUMO
O objetivo deste experimento foi produzir uma infecção experimental de Salmonella enterica subespécie. enterica sorotipo Panama e verificar a importância da via nasonasal na transmissão entre leitões desmamados. Foram utilizados seis leitões recém-desmamados, adquiridos de granja livre de Salmonella spp. Utilizaram-se baias isoladoras, que proporcionavam o contato nasonasal e eliminavam a possibilidade de outras vias de transmissão e de contaminação externa. Três grupos foram formados: controle, sentinela e infectado. Não foram encontradas amostras positivas para Salmonella spp. em leitões do grupo-controle e sentinelas, e nos animais infectados foi isolada Salmonella Panama em suabes retais e tecidos necropsiados. Os resultados revelaram não haver a transmissão pela via nasonasal entre leitões desmamados, pois, em nenhum momento, o agente foi isolado dos animais sentinelas.
\end{abstract}

Palavras-chave: suíno, infecção experimental, Salmonella Panama, transmissão naso-nasal

\begin{abstract}
Experimental infection of Salmonella enterica ssp. enterica serovars Panama was proceeded to establish the importance of nose-to-nose contact in the transmission among weaned pigs. Six recently-weaned pigs were acquired from a farm previously selected, free from Salmonella spp. Isolation stalls allowing noseto-nose contact and eliminating other transmission routes as well outside contamination were used. Three groups were formed: control, sentinel, and infected. Piglets of control and sentinel groups were not positive for Salmonella spp., however, Salmonella Panama was isolated in infected animals in rectal swabs and necropsied tissues. It was concluded that there was not transmission by nose-to-nose contact among weaned pigs, since Samonella Panama was not isolated in the sentinel group at any moment.
\end{abstract}

Keywords: swine, experimental infection, Salmonella Panama, nose-to-nose transmission

\section{INTRODUÇÃO}

O maior entrave no controle das infecções por Salmonella spp. nas granjas de suínos é, principalmente, a falta de conhecimentos sobre a epidemiologia da infecção nos sistemas modernos de criação. Devido ao fato de Salmonella spp. ser eliminada nas fezes dos animais infectados, a via fecal-oral é considerada a base da transmissão do patógeno (Fedorka-

Recebido em 26 de março de 2009

Aceito em 11 de outubro de 2010

E-mail: lgoliveira@fcav.unesp.br
Cray et al., 2000). Em experimentos com suínos inoculados, notou-se que há eliminação de grande número de bactérias nas fezes, por períodos prolongados (Wood et al., 1989). Suínos suscetíveis, quando colocados em ambientes que contenham fezes contaminadas, geralmente adquirem a infecção (Fedorka-Cray et al., 1994; Hurd et al., 2001). Adicionalmente, a transmissão por meio do contato nasonasal é admitida em razão da presença do patógeno nas secreções orofaríngeas (Schwartz, 1999). 
O fato de Salmonella ser, frequentemente, isolada de partículas de poeira em granjas suínas (Rajic et al., 2005) bem como sua capacidade de manter-se viável por longos períodos em aerossóis (McDermid e Lever, 1996) sugerem a possibilidade de transmissão aerógena entre suínos. De fato, a principal forma de transmissão é pela via fecal-oral, porém há confirmação experimental da transmissão aerógena de Salmonella enterica na espécie suína (Oliveira et al., 2006), em frangos (Lever e Willians, 1996), ratos e bezerros (Wathes et al., 1988).

As secreções orofaríngeas de animais infectados podem conter salmonelas, o que possibilita a transmissão por contato direto. O contato direto entre animais infectados e não infectados por Salmonella spp. é considerado a principal via de transmissão entre suínos criados intensivamente. Estudos experimentais indicam diferenças entre os sorotipos de Salmonella spp. na transmissão pelo contato nasonasal. Trabalhos que usaram de metodologia semelhante provaram que $S$. Typhimurium pode ser transmitida pelo contato nasonasal enquanto $S$. Derby e $S$. Agona, não (Freschi, 2007; Oliveira et al., 2007).

Nos suínos, a salmonelose pode se manifestar, clinicamente, como uma septicemia aguda ou como uma enterocolite aguda ou crônica (Sobestiansky et al., 1999). Suínos que sobrevivem à septicemia aguda podem desenvolver sinais clínicos devido às lesões localizadas, como pneumonia, hepatite, enterocolite e, ocasionalmente, meningoencefalite. Animais com enterocolite poderão apresentar definhamento crônico. Os suínos podem recuperar-se totalmente, mas alguns poderão permanecer como portadores e excretores intermitentes por meses (Schwartz, 1999).

Os sorotipos que não causam doença clínica no suíno, porém, são os que têm maior importância para a segurança alimentar, uma vez que o animal portador não apresenta sinais clínicos, mas é uma fonte permanente de eliminação do agente, desde a granja até o processamento industrial. Os sorotipos não adaptados, ou salmonelas paratíficas, na maioria das vezes, são imperceptíveis dentro do sistema de produção. Contudo, são responsáveis por condenação de carcaças e devolução de carregamentos destinados à exportação, constituindo grandes perdas aos produtores e exportadores envolvidos (Gresham, 1996).

O isolamento microbiológico é o método mais utilizado para detecção de Salmonella, por ser muito difundido, seguro e relativamente barato. Este constitui uma ferramenta valiosa e, até o momento, insubstituível, considerada a importância das informações epidemiológicas baseadas em características fenotípicas e genotípicas identificáveis pela cultura. Entretanto, a intermitência da eliminação de Salmonella nas fezes e períodos longos de análise são os fatores que podem comprometer a utilização do isolamento como técnica de rotina para o monitoramento de Salmonella em granjas suínas (Funk et al., 2000).

A sorologia pode ser uma ferramenta fundamental para um programa de controle, pois pode auxiliar rápida e corretamente na identificação de rebanhos positivos (Alban et al., 2002). Assim, se o objetivo for identificar todos os rebanhos que foram expostos à Salmonella spp., a sorologia pode ser aplicada, ao invés do isolamento microbiológico (Sandberg et al., 2002). Portanto, o teste sorológico fornece uma estimativa do número de animais que foram, em algum momento da produção, expostos ao agente. Existe um desafio na questão de associar a sorologia com o isolamento microbiológico, pois os resultados sorológicos de um rebanho podem ser interpretados diferentemente, conforme o ponto de corte aplicado ao se avaliar o teste (Alban et al., 2002). Outro ponto a ser considerado é que o isolamento de Salmonella spp. indica infecção e excreção, enquanto a sorologia positiva pode indicar a transmissão silenciosa no rebanho (Van Winsen et al., 2001). Portanto, as estimativas de prevalência de Salmonella, obtidas por sorologia e bacteriologia, podem diferir (Fedorka-Cray et al., 1997; Silva et al., 2003). Contudo, conhece-se a diversidade de sorotipos de Salmonella spp. que podem estar presentes nos suínos. A maior dúvida seria responder se, experimentalmente, outro sorotipo seria capaz de tal transmissão.

Este trabalho teve como objetivo avaliar a possibilidade de transmissão pela via naso-nasal de Salmonella enterica subespécie enterica sorotipo Panama em leitões desmamados, por meio de indução da infecção experimentalmente. 


\section{Oliveira et al.}

\section{MATERIAL E MÉTODOS}

Foram utilizados seis leitões, provenientes de granja previamente selecionada, aumentando, dessa forma, a possibilidade da aquisição de animais livres de Salmonella spp. A granja selecionada atendeu aos princípios de biosseguridade, de acordo com o Ministério da Agricultura, indicado para a avaliação das Granjas de Reprodutores Suídeos Certificadas (GRSC), presente na Instrução Normativa $\mathrm{n}^{\circ} 19$ de 2002 do MAPA (Brasil..., 2002). Também, foram avaliados a porca e o piso da cela parideira, com o objetivo de confirmar a não exposição dos leitões a Salmonella spp. Da porca colheu-se amostra de sangue para sorologia e fezes do reto para avaliação microbiológica. Com o mesmo propósito, colheu-se amostra de resíduos do piso da cela de parição. O experimento foi avaliado pela Comissão de Ética e Bem-Estar Animal, da UNESP/Jaboticabal, processo 022052/10.

Os animais foram escolhidos, aleatoriamente, de uma única leitegada, sendo quatro fêmeas e dois machos, com 21 dias de idade e média de peso de 5,2kg. Esses leitões foram alojados em gaiolas suspensas, individuais, e monitorados bacteriologicamente. O monitoramento foi feito durante sete dias, sendo realizada microbiologia de amostras retais no primeiro, quarto e sétimo dias, e avaliação sorológica para confirmação da condição livre de Salmonella spp. As gaiolas individuais de alojamento foram previamente lavadas e desinfetadas. Amostras da ração e água fornecidas aos leitões também foram colhidas para avaliação microbiológica.

Após o período de monitoramento, os seis leitões foram, aleatoriamente, distribuídos em três grupos e alojados nos isoladores: 1) grupo 1: controle; 2) grupo 2: animais sob inoculação; e 3) grupo 3: animais sentinelas. Foram empregados isoladores de aço inoxidável $(0,80 \mathrm{~m}$ x $0,80 \mathrm{~m} \times 1,30 \mathrm{~m})$ fechados, projetados para estudos epidemiológicos. O modelo foi desenvolvido a partir de protótipo desenvolvido por Torremorell et al. (1997), para estudos de transferência aérea de microrganismos (Fig. 1).

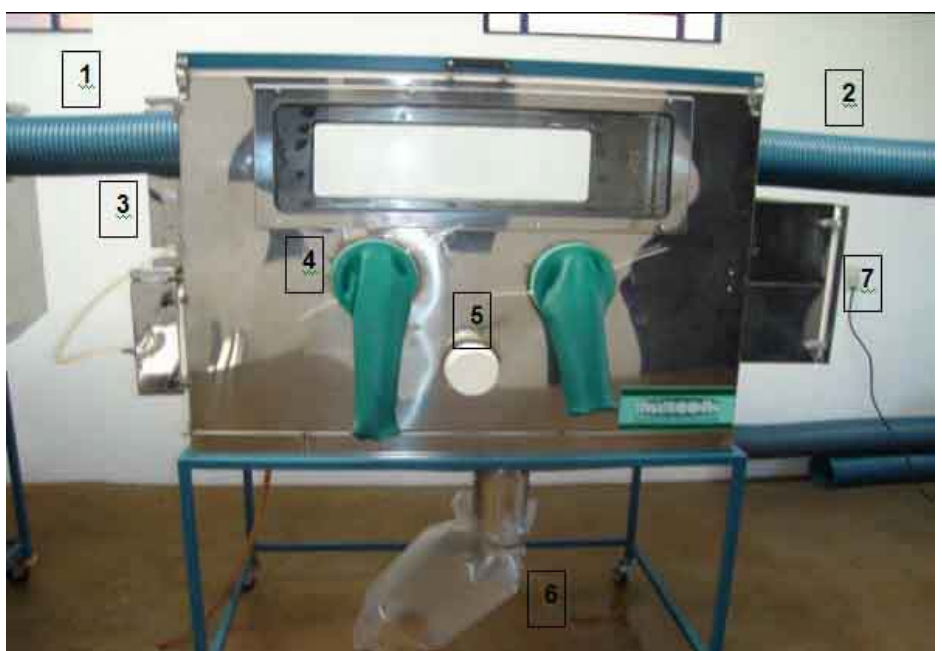

Figura 1. Isolador usado no experimento. 1: entrada de ar do sistema; 2: saída de ar; 3: reservatório de água; 4: luvas de borracha para manipulação interna; 5: orifício para conexão com outro isolador (contato nasonasal); 6: saco para a coleta dos dejetos; 7: caixa de passagem, dotada de portas interna e externa.

A lavagem e desinfecção dos isoladores foram criteriosas, o procedimento de lavagem foi feito uma vez, e o de desinfecção, repetido por três vezes, com intervalo de um dia. Utilizou-se, primeiramente, solução detergente, juntamente com água pressurizada na lavagem do equipamento. Assim que as superfícies secaram, foram submetidas à desinfecção com etanol a $70 \%$ e subsequente uso de solução comercial de glutaraldeído a 2\% e amônia quaternária. Após a última pulverização das superfícies internas dos isoladores, estes permaneceram completamente fechados por dois dias. Procedeu-se, então, à fumigação com o sistema fechado, um dia antes 
da entrada dos animais. A escolha do glutaraldeído baseou-se no fato de não ser agressivo para superfícies metálicas, ser aceito como esterilizante químico em ambientes hospitalares e ter eficiência comprovada contra Salmonella spp. (Rutala, 1995). Para a garantia da esterilidade para Salmonella spp., foi realizado, após esse procedimento de limpeza e desinfecção, uma colheita de material, por meio de suabes, para o isolamento microbiológico das paredes, piso e cochos. O resultado foi negativo quanto à presença deste microrganismo.

O sistema de isoladores foi projetado para que houvesse fluxo de ar, no sentido do isolador 3 (leitões sentinelas) para o 2 (leitões inoculados), impedindo que os leitões sentinela fossem infectados por contaminação aérea. Admitiu-se que, se fosse registrada a transferência da infecção, o agente teria sido transferido exclusivamente por meio do contato nasonasal entre os animais. Os animais controle foram mantidos em isolador exclusivo, sem qualquer conexão com os demais.

Toda a água fornecida aos animais foi previamente autoclavada e colocada no reservatório de água do sistema, que se conectava a um bebedouro interno, no isolador. A ração experimental foi formulada livre de farinhas de origem animal e antibióticos promotores de crescimento. Tanto a água quanto a ração foram submetidas à análise bacteriológica para presença de Salmonella spp. Foram realizadas duas análises no período préinoculação e outras três no período pósinoculação.

Amostras de Salmonella enterica, sorotipo Panama, cedidas pelo Laboratório de Microbiologia da Embrapa Aves e Suínos de Concórdia, SC e mantidas em sua coleção sob $n^{\circ}$ 8193, foram usadas na preparação do inóculo. Os inóculos foram preparados de acordo com Wood et al. (1991). Após cultivo a $37^{\circ} \mathrm{C}$ por 18 horas, separaram-se duas alíquotas de três mililitros cada, que foram utilizadas para a inoculação dos leitões. A concentração de bactérias no inóculo, determinada pela técnica de drop-counting (Miles e Misra, 1938), foi de 2,16 X $10^{10}$ $\mathrm{UFC} / \mathrm{mL}$.
Os leitões foram mantidos em jejum alimentar e hídrico por 18 horas, antes da administração do inóculo. A ração e a água foram fornecidas 30 minutos após a inoculação. Inóculos ou placebos foram administrados, via oral, utilizando-se seringas estéreis descartáveis. Os suínos controle (C1 e C2) e sentinelas (S3 e S4) receberam solução de caldo Luria Bertani estéril (3mL) e foram imediatamente colocados nos isoladores 1 (Iso 1) e 3 (Iso 3), respectivamente. Os suínos do grupo 2 (I5 e I6) receberam o inóculo contendo Salmonella Panama ${ }^{\mathrm{Nal}+}$ e foram alojados no isolador 2 (Iso2). O sistema foi fechado e mantido por 14 dias.

A colheita de amostras foi realizada diariamente, de todos os animais. Com o emprego de suabes, foram coletadas amostras de fezes do reto. Amostras de sangue, de todos os leitões, foram colhidas no período pré-inoculação. Repetiu-se tal procedimento ao final do período experimental. As amostras foram analisadas por ELISA.

Ao final dos 14 dias nos isoladores, os animais, submetidos à eutanásia, foram necropsiados, conforme indicado por Sobestiansky et al. (2005). Foram colhidos fragmentos de linfonodos mandibulares, tonsilas, pulmões, fígado, baço, linfonodos ileocólicos, linfonodos mesentéricos, jejuno, íleo e conteúdo do ceco. Os suabes retais foram imediatamente enviados para análise microbiológica (Freschi, 2007). As amostras de tecido foram processadas de acordo com protocolo descrito por Hurd et al. (2001). O ELISA indireto, das amostras de sangue dos suínos, foi realizado no Laboratório de Microbiologia da Embrapa.

\section{RESULTADOS E DISCUSSÃO}

Não foram encontradas amostras positivas para Salmonella spp. dos suabes retais colhidos dos leitões do grupo 1 e do grupo 3. No entanto, nos leitões sob inoculação (I5 e I6), foram isolados Salmonella Panama ${ }^{\text {Nal+ }}$ em praticamente todas as colheitas (Tab. 1). Observou-se, durante todo o período pós-inoculação, que os leitões inoculados (I5 e I6) apresentavam sinais clínicos aparentes de uma infecção entérica e desenvolvimento de quadros de diarreia. 


\section{Oliveira et al.}

Tabela 1. Resultados da detecção de Salmonella Panama ${ }^{\mathrm{Nal}+}$, pelo isolamento bacteriológico a partir de amostras de suabes retais colhidos, individualmente, de suínos, nos isoladores

\begin{tabular}{|c|c|c|c|c|c|c|}
\hline \multirow{3}{*}{ Dia } & \multicolumn{3}{|c|}{ Isolador 1} & & \multicolumn{2}{|c|}{ Isolador 3} \\
\hline & & & & & & \\
\hline & C1 & $\mathrm{C} 2$ & I5 & I6 & S3 & S4 \\
\hline 1 & - & - & - & + & - & - \\
\hline 2 & - & - & + & - & - & - \\
\hline 3 & - & - & - & + & - & - \\
\hline 4 & - & - & - & - & - & - \\
\hline 5 & - & - & + & - & - & - \\
\hline 6 & - & - & + & + & - & - \\
\hline 7 & - & - & + & + & - & - \\
\hline 8 & - & - & + & + & - & - \\
\hline 9 & - & - & + & + & - & - \\
\hline 10 & - & - & + & + & - & - \\
\hline 11 & - & - & + & - & - & - \\
\hline 12 & - & - & - & - & - & - \\
\hline 13 & - & - & + & - & - & - \\
\hline 14 & - & - & - & + & - & - \\
\hline
\end{tabular}

No exame macroscópico dos órgãos dos suínos, não foi verificada qualquer alteração. Ao exame microbiológico dos tecidos necropsiados, nos animais dos grupos controle e sentinela, não foi

Tabela 2. Resultados da detecção de Salmonella Panama ${ }^{\mathrm{Nal}+}$, pelo isolamento bacteriológico a partir de amostras de tecidos

\begin{tabular}{|c|c|c|c|c|c|c|}
\hline \multirow{2}{*}{ Tecido } & \multicolumn{2}{|c|}{ Grupo 1} & \multicolumn{2}{|c|}{ Grupo 2} & \multicolumn{2}{|c|}{ Grupo 3} \\
\hline & $\mathrm{C} 1$ & $\mathrm{C} 2$ & I5 & I6 & S3 & S4 \\
\hline Linfonodos mandibulares & - & - & + & + & - & - \\
\hline Tonsilas & - & - & + & + & - & - \\
\hline Pulmões & - & - & + & + & - & - \\
\hline Fígado & - & - & + & + & - & - \\
\hline Baço & - & - & + & + & - & - \\
\hline Linfonodos ileocólicos & - & - & + & + & - & - \\
\hline Linfonodos mesentéricos & - & - & + & + & - & - \\
\hline Jejuno & - & - & + & + & - & - \\
\hline Íleo & - & - & + & + & - & - \\
\hline Conteúdo do сесо & - & - & - & + & - & - \\
\hline
\end{tabular}

( - ), negativo; ( + ), positivo. isolada Salmonella spp. Ao contrário, nos do grupo sob inoculação, as análises revelaram-se positivas (Tab. 2). 
Como pode ser visto, três pares de leitões foram alojados isoladamente, cada qual em uma câmara de isolamento. Os leitões do grupo-controle ocuparam uma das câmaras que recebeu aeração própria. Os leitões dos grupos infectado e sentinela ocuparam, cada qual, uma câmara, e a aeração para estes foi conjunta. Assim, o ar, inicialmente, entrava na câmara dos animais sentinelas e desta passava para a câmara contígua, que alojava os leitões infectados. A transferência do ar era feita por meio de um orifício que permitia a comunicação entre as duas câmaras. O orifício, elevado do piso e com diâmetro adequadamente projetado, permitia apenas que os animais de uma baia tocassem, com o focinho, os animais da baia contígua. Admitiu-se, com este planejamento experimental, que, se a infecção fosse transferida dos animais infectados para os animais sentinelas, o fato seria decorrente do contato nasonasal ocorrido entre os animais dos dois grupos.

De acordo com Schwartz (1999), a etiologia da infecção pode decorrer do contato com secreções nasais ou com as fezes que, muito frequentemente, podem estar presentes no focinho dos animais. As salmonelas podem ser facilmente isoladas de descargas nasais de suínos infectados. Há comprovação de que os tecidos linfoides nasais associados são importantes locais de invasão para $S$. Typhimurium em suínos, favorecendo a via de contaminação (Fedorka-Cray et al., 1995). Também, o comportamento de fuçar dos suínos, habitualmente, favorece a presença de material fecal nas cavidades nasais (Baskerville e Dow, 1973).

A infecção, entretanto, não se transferiu, fato que corrobora as observações de Freschi (2007), em seu estudo com $S$. Derby, e de Oliveira et al. (2007), com S. Agona, e diverge do achados de Oliveira et al. (2007), com S. Thyphimurium. Muitas seriam as causas a justificar os resultados observados. A não infecção dos leitões inoculados, o não contato entre os leitões das duas baias, a baixa virulência ou o baixo título de eliminação do agente nas fezes seriam, possivelmente, as justificativas mais plausíveis.

Como demonstram os resultados apresentados na Tab. 1, a infecção dos leitões foi satisfatoriamente induzida. Já no primeiro dia pós-inoculação, foi possível isolar o agente das fezes dos animais inoculados, e sua eliminação nas fezes persistiu durante todo o período, o que corrobora com as observações de Fedorka-Cray et al. (1994), Oliveira et al. (2006), Freschi (2007) e Oliveira et al. (2007). Foi possível evidenciar a intermitência na eliminação da salmonela. Interessante é observar que, do sexto dia pós-inoculação ao $10^{\circ}$ dia, os dois animais inoculados excretaram salmonela constantemente, sugerindo um pico de excreção.

Os resultados mostrados na Tab. 2 revelaram que não apenas a infecção se efetivou, mas se difundiu além dos limites gastrintestinais, já que a bactéria inoculada pode ser recuperada de linfonodos e de diversos órgãos internos, duas semanas após a inoculação. Obteve-se, pois, uma infecção sistêmica, fato que caracteriza o sorotipo como relativamente virulento. Uma diferença importante dos outros ensaios realizados foi que a cepa utilizada (Salmonella Panama) era oriunda de isolados de linfonodos mesentéricos de animais de campo e a dose inoculada foi maior que as usadas nos demais experimentos $\left(2,16 \times 10^{10} \mathrm{UFC} / \mathrm{mL}\right)$.

O modelo experimental empregado já foi testado anteriormente (Freschi, 2007; Oliveira et al., 2007). Porém, neste ensaio havia uma diferença. No sistema usado nos trabalhos anteriores, não era possível fazer a colheita de fezes diretamente no reto dos animais, pois a montagem do sistema não permitia, e, então, somente foi feita a colheita de fezes a partir do saco de dejetos. Para este estudo, os isoladores foram adaptados de modo a viabilizar colheitas diárias de fezes diretamente do reto dos animais.

Os resultados obtidos por Oliveira et al. (2007), que observaram a transferência da infecção pela via nasonasal de Salmonella enterica subespécie enterica sorotipo Typhimurium, indicaram a aplicabilidade do modelo (validade para outros sorotipos). Também, estes resultados sugerem que ocorreu o contato nasonasal entre os leitões. Vale ressaltar, ainda, que, em todos os estudos em que foi empregado o presente modelo, foi possível observar que os animais das duas baias se tocavam várias vezes ao dia.

O ELISA realizado detectou a presença de anticorpos maternais em três dos seis leitões, no período pré-inoculação, assim como na porca 
mãe, evidenciando o contato da porca, em alguma ocasião de sua vida, com Salmonella spp. e a transferência dessa imunidade aos leitões.

Os isolamentos microbiológicos, realizados no período pré-inoculação, asseguram que, naquele momento, não havia circulação do patógeno. Já ao final do experimento, todos os animais foram negativos, inclusive os infectados, resultado que corrobora com Van Der Wolf et al. (2001) e Van Der Gaag et al. (2004), que demonstraram a soroconversão para Salmonella spp. aos 21 dias pós-infecção, sendo que, neste ensaio, foram 14 dias pós-inoculação. A eliminação de quantidades insuficientes do agente nas fezes ou a sua baixa transmissibilidade, possivelmente, representam as melhores justificativas para os resultados obtidos neste trabalho.

\section{CONCLUSÕES}

A infecção experimental de suínos com Salmonella enterica subespécie enterica sorotipo Panamá é possível e pode produzir infecção sistêmica em leitões jovens. A biologia e as características dos diversos sorotipos de Salmonella spp. são realmente diversificadas, e os resultados até aqui obtidos sugerem que estudos devem ser realizados para se obter a compreensão deste importante tema.

\section{REFERÊNCIAS BIBLIOGRÁFICAS}

ALBAN, L.; STEGE, H.; DAHL, J. The new classification system for slaughter-pig herds in the Danish Salmonella surveillance-and-control program. Prev. Vet. Med., v.53, p.133-146, 2002.

BASKERVILLE, A.; DOW, C. Pathology of experimental pneumonia in pigs produced by Salmonella cholerae-suis. J. Comp. Pathol., v.83, p.207-215, 1973.

BRASIL. Ministério da Agricultura Pecuária e Abastecimento. Instrução Normativa $n^{0} 19$ de $2002 . \quad$ Disponível em: $<$ http://extranet.agricultura.gov.br/sislegisconsulta/consultarLegislacao.do $>$. Acessado em: 25 out. 2007.

FEDORKA-CRAY, P.J.; WHIPP, S.C.; ISAACSON, R.E. et al. Transmission of Salmonella typhimurium to swine. Vet. Microbiol., v.41, p.333-344, 1994.
FEDORKA-CRAY, P.J.; KELLEY, L.C.; STABEL, T.J. et al. Alternative routes of invasion may affect pathogenesis of Salmonella typhimurium in swine. Infect. Immunol., v.63, p.2658-2664, 1995.

FEDORKA-CRAY, P.; McKEAN, J.D.; BERAN, G.W. Prevalence of Salmonella in swine and pork: a farm to consumer study. ISU Swine Research Report, 1997. Disponível em: $<$ http://www.wxtension.iastate.edu/Pages/ansci/s winereports/asl-1507.pdf $>$. Acessado em: 15 out. 2007.

FEDORKA-CRAY, P.J.; GRAY, J.T.; WRAY, C. Salmonella infections in pigs. In: WRAY, C.; WRAY, A. (Ed.) Salmonella in domestic animals. Oxford: Oxford University, 2000. p.191-207.

FRESCHI, C.R. Investigação experimental sobre a transmissão aerógena e nasonasal de Salmonella enterica subespécie enterica sorotipo Derby em suínos. 2007. 60f. Tese (Doutorado) Faculdade de Ciências Agrárias e Veterinárias, Universidade Estadual Paulista, Jaboticabal, SP.

FUNK, J.A.; DAVIES, P.R.; NICHOLS, M.A. The effect of fecal sample weight on detection of Salmonella enterica in swine faces. J. Vet. Diagn. Invest., v.12, p.412-418, 2000.

GRESHAM, A.C.J. An old disease of increasing significance-Salmonella infeccion in pigs in Great Britain. Pig J., v.37, p.59-64, 1996.

HURD, H.S.; GAILEY, J.K.; McKEAN, J.D. et al. Rapid infection in market-weight swine following exposure to a Salmonella Typhimurium-contamined environment. Am. J. Vet. Res., v.62, p.1194-1197, 2001.

LEVER, M.S.; WILLIAMS, A. Cross infection of chicks by airborne transmission of Salmonella enteritidis PT4. Lett. Appl. Microbiol., v.23, p.347-349, 1996.

McDERMID, A.S.; LEVER, M.S. Survival of Salmonella Enteritidis PT4 and S. Typhimurium Swindon in aerosols. Lett. Appl. Microbiol., v.23, p.107-109, 1996.

MILES, A.A.; MISRA, S.S. The estimation of the bactericide power of the blood. J. Hyg., v.38, p.732-739, 1938. 
OLIVEIRA, C.J.B.; CARVALHO, L.F.O.S.; GARCIA, T.B. Experimental airborne transmission of Salmonella Agona and Salmonella Typhimurium in weaned pigs. Epidemiol. Infect., v.134, p.199-209, 2006.

OLIVEIRA, C.J.B.; GARCIA, T.B.; CARVALHO, L.F.O.S. et al. Nose-to-nose transmission of Salmonella Typhimurium between weaned pigs. Vet. Microbiol., v.125, p.355-361, 2007.

RAJIC, A.; CHOW, E.Y.W.; WU, J.T.Y. et al. Longitudinal study of Salmonella species in 90 Alberta swine finishing farms. Vet. Microbiol., v.105, p.47-56, 2005.

RUTALA, W.A. Antisepsis, disinfection and sterilization in hospitals and related institutions. In: MURRAY, P.R.; BARON, E.J.; PFALLER, M.A. et al. (Eds). Manual of clinical microbiology. 6.ed. Washington: ASM, 1995. p.227-295.

SANDBERG, M.; HOPP, P.; JARP, J. et al. An evaluation of the Norwegain Salmonella surveillance and control program in live pig and pork. Int. J. Food Microbiol., v.72, p.1-11, 2002.

SCHWARTZ, K.J. Salmonellosis. In: STRAW, B.E; D'ALLAIRE, S.; MENGELING, W.L. et al. Diseases of swine. 9.ed. Oxford: Blackwell Science, 1999. p.535-551.

SILVA, L.E.; GORTADI, C.; MOSTARDEIRO, P. et al. Estudo longitudinal da infecção por Salmonella em um sistema de produção de suínos. In: CONGRESSO DE VETERINARIOS ESPECIALISTAS EM SUINOS, 11., 2003, Goiânia. Anais... Goiânia, 2003.

SOBESTIANSKY, J.; BARCELLOS, D.; MORES, N. et al. (Eds). Clínica e Patologia Suína. 2.ed. Goiânia: [s.n.], 1999. 464p.

SOBESTIANSKY, J.; BARCELLOS, D.; MORENO, A.M. et al. (Eds). Suínos - colheita e remessa de materiais para laboratórios para fins de diagnóstico. 1.ed. Goiânia: [s.n.], 2005.
TORREMORELL, M.; PIJOAN, C.; JANNI, K. et al. Airborne transmission of Actinobacillus pleuropneumoniae and porcine reproductive and respiratory syndrome virus in nursery pigs. Am. J. Vet. Res., v.58, p.828-832, 1997.

VAN DER GAAG, M.A.; VOS, F.; SAATKAMP, H.W. et al. A state-transition simulation model for the spread of Salmonella in the pork supply chain. Eur. J. Oper. Res., v.156, p.782-798, 2004.

VAN DER WOLF, P.J.; WOLBERS, W.B.; ELBERS, A.R. et al. Herd level husbandry factors associated with the serological Salmonella prevalence in finishing pig herds in The Netherlands. Vet. Microbiol., v.78, p.205219, 2001.

VAN WINSEN, R.L.; VAN NES, A.; KEUZENKAMP, D. et al. Monitoring of transmission of Salmonella enterica serovars in pigs using bacteriological and serological detection methods. Vet. Microbiol., v.80, p.267274, 2001.

WATHES, C.M.; ZAIDAN, W.A.R.; PEARSON, G.R. et al. Aerosol infection of calves and mice with Salmonella typhimurium. Vet. Rec., v.123, p.590-594, 1988.

WILCOCK, B.P.; SCHWARTZ, K.J. Salmonellosis. In: LEMAN, A.D.; STRAW, B.E.; MENGELING, S.D. (Eds). et al. Diseases of swine. 7.ed. Iowa: Iowa State University, 1992. p.570.

WOOD, R.L.; POSPISCHIL, A.; ROSE, R. Distribution of persistent Salmonella thyphimurium infection in internal organs of swine. Am. J. Vet. Res., v.50, p.1015-1021, 1989.

WOOD, R.L.; ROSE, R.; COE, N.E. et al. Experimental establishment of persistent infection in swine with a zoonotic strain of Salmonella Newport. Am. J. Vet. Res., v.52, p.813-819, 1991. 